\title{
Ultrastructural Immunolabeling Shows Prominent Presynaptic Vesicular Localization of $\delta$-Opioid Receptor within Both Enkephalin- and Nonenkephalin-Containing Axon Terminals in the Superficial Layers of the Rat Cervical Spinal Cord
}

\author{
P. Y. Cheng, ${ }^{1}$ A. L. Svingos, ${ }^{1}$ H. Wang, ${ }^{1}$ C. L. Clarke, ${ }^{1}$ S. Jenab, ${ }^{2}$ I. W. Beczkowska, ${ }^{2}$ C. E. Inturrisi, ${ }^{2}$ and V. M. \\ Pickel $^{1}$ \\ 'Department of Neurology and Neuroscience and 'Department of Pharmacology, Cornell University Medical \\ College, New York, New York 10021
}

Opioid peptides, Met5- and Leus-enkephalin, are known endogenous ligands for the $\delta$-opioid receptor (DOR) associated with opioid analgesia at the spinal level. To determine the cellular sites for DOR-mediated actions, we examined the ultrastructural localization of DOR and Met $^{5}$-enkephalin (ME) in the spinal cord by combining immunoperoxidase and immunogold-silver labeling for antibodies against DOR and ME, respectively. Antibodies for DOR localization were raised in guinea pig against peptide 34-47 (p34), an amino acid sequence within the extracellular N-terminus of the DOR recently cloned from mouse neuroblastoma glioma (NG-108) cells. Selective immunoperoxidase labeling for DOR was detected by light microscopy in NG-108 cells and in the lamina I and II of the dorsal horn of the spinal cord (C2-C4). Electron microscopy of these spinal laminae revealed that the majority of the punctate varicosities seen by light microscopy were axon terminals. $\delta$-opioid receptor-like immunoreactivity (DOR-LI) in axon terminals was most prominently associated with large dense core vesicles, and sometimes seen along the membranes of small clear vesicles and segments of the plasmalemma. A semiquantitative analysis of dually labeled sections revealed that of the terminals showing DOR-LI, $23 / 102(23 \%)$ also contained Met $^{5}$-enkephalin-like immunoreactivity (ME-LI). Conversely, 23/35 (66\%) of the terminals showing ME-LI also showed DOR-LI. In addition to the presynaptic localization, selective postsynaptic densities within dendrites were also occasionally $(9 \%)$ immunolabeled for the opioid receptor. These results provide the first ultrastructural evidence that DOR may serve autoreceptor functions on ME terminals as well as presynaptic modulation of other transmitters in the dorsal horn of the rat spinal cord. Additionally, the vesicular localization of DOR-LI in axon terminals

Received Jan. 26, 1995; revised Mar. 29, 1995; accepted Apr. 25, 1995

This work was supported in part by Aaron Diamond Postdoctoral Fellowslips to P.Y.C. and A.L.S., NIDA Gıant DA04600, NIH HL 18974, and Caleer Award from NIMH MHO0078 to V.M.P., as well as DA07274, DA01457, and DA00198 to C.E.I. We are grateful to T. Ziegler and S. Chew for technical assistance, and Drs. T. Patterson and C.T. Drake for providing the $k$ receptor peptides.

Correspondence should be addressed to Peter Y. Cheng, Ph.D., Department of Neurology and Neuroscience, 411 East 69th Street, Cornell University Medical College, New York, NY 10021.

Copyright $\odot 1995$ Society for Neuroscience $0270-6474 / 95 / 155976-13 \$ 05.00 / 0$ suggests the involvement of these organelles in the transport of the receptors to the plasma membrane.

[Key words: opioid receptors, coexistence, dorsal horn, autoreceptor, ultrastructure, opioids, presynaptic receptor, postsynaptic receptor, vesicles]

The analgesic properties of opiates are well known. The superficial layers of the dorsal horn in the spinal cord, the point of entrance of nociceptive primary sensory information, are thought to be important sites for the production of antinociception by both $\mu$ - and $\delta$-opioid receptor agonists (Yaksh, 1993). This is supported by both autoradiographical localization of opioid binding sites (Atweh and Kuhar, 1983) and immunocytochemical localization of the endogenous opioid peptides Met ${ }^{5}$ and $\mathrm{Leu}^{5}$-enkephalin to these areas (Hunt et al., 1980). Within laminae I-II, enkephalin-like immunoreactivity (ENK-LI) is intensely localized to axonal varicosities presynaptic to dendrites or cell bodies (Ribeiro-da-Silva et al., 1991). In this region, the enkephalin-labeled terminals also occasionally contact other vesicle-containing profiles believed to be axonal varicosities (Hunt et al., 1980; Bennett et al., 1982).

In the dorsal horn of the spinal cord, opioids are thought to elicit both pre- and postsynaptic effects. Evidence for the presynaptic modulation is supported by receptor binding and physiological studies. Dorsal rhizotomy leads to a reduction of both $\mu$ - and $\delta$-opioid receptor binding in the dorsal horn (Fields et al., 1980; Zajac et al., 1989), suggesting that a population of opioid receptors are localized on primary afferent terminals. Further evidence for this presynaptic localization is provided by the demonstration of the depressive effects of opioid agonists on the activity of nociceptive dorsal horn neurons (Le Bars et al., 1976; Duggan et al., 1977; Andersen et al., 1978; Randic and Miletic, 1978; Grudt and Williams, 1994). In particular, the analgesic efficacy of stabilized enkephalin analogs at the spinal cord level (Yaksh et al., 1978) strongly supports the involvement of endogenous opioids and DOR in spinal analgesia. Finally, a presynaptic localization of opioid receptors is also suggested by the ability of opioid receptor agonists to inhibit the relcase of ncurotransmitters from primary afferent neurons (Go and Yaksh, 1987; Collin et al., 1991; Kangrga and Randic, 1991). Despite the abundance of evidence that the opioid receptors may presynaptically modulate the release of transmitters within primary afferents, it is not known whether these receptors serve similar functions with respect to collaterals of local neurons or afferents 
to the dorsal horn from other regions of the spinal cord (Hylden et al., 1989; Morgan et al., 1991).

The postsynaptic function of opioid receptors is suggested by the ability of opioid receptor agonists to inhibit the excitation of dorsal horn neurons produced by the iontophoretic application of excitatory amino acids (Belcher and Ryall, 1978; Zieglgansberger and Tulloch, 1979; Willcockson et al., 1984). A postsynaptic localization of opioid receptors is also indirectly supported by immunocytochemical data showing that enkephalin-LI terminals form synapses with dendrites and cell bodies within the dorsal horn (Bennett et al., 1982; Sumal et al., 1982).

Presently, there is no ultrastructural evidence for pre- or postsynaptic localization of the DOR, nor has its cellular relationship with endogenous opioid peptides in spinal cord interneurons been established. To more selectively examine the cellular sites of distribution of the DOR, we produced and characterized antisera against an extracellular fragment of the $\mathrm{N}$-terminal portion of the receptor. This peptide, corresponding to amino acids 3447 (p34), is found in the cloned DOR from mouse neuroblastoma glioma NG-108 cells (Evans et al., 1992; Kieffer et al., 1994) and from rat olfactory bulb (Abood et al., 1994), but is not found in the peptide sequence of the cloned $\mu$-or $\kappa$-opioid receptors (Abood et al., 1994). The results of the ultrastructural analysis revealed a prominent vesicular and plasmalemmal localization of DOR within axon terminals and less frequent localization to postsynaptic dendrites within layers I and II of the dorsal horn of the rat cervical spinal cord (C2-C4). Using combined immunoperoxidase and immunogold-silver labeling, we demonstrated that the majority of ME-LI axon terminals contained DOR, whereas many $\delta$-opioid receptor immunoreactivities (DOR-IR) were without detectable ME immunoreactivity (ENK-IR).

\section{Materials and Methods}

Production of antiserum. Three peptides representing sequences within the cDNA-deduced primary structure of the mouse DOR were synthesized and antisera generated in guinea pig (Immuno-Dynamics, Inc., La Jolla, CA). The peptide sequences were chosen based on predictions of antigenicity (Jameson-Wolf method) and absence of sequence homology with other known proteins. Peptide p34 corresponds to amino acids $34-47$, an extracellular fragment within the N-terminus; peptide p151 corresponds to amino acids 151-160 within the second cytoplasmic loop; and peptide 247 corresponds to amino acids $247-260$ within the third cytoplasmic loop (Evans et al., 1992). For production of polyclonal antisera against p34 a cysteine was added, whereas p151 already contained a terminal cysteine residue. The sequence for p34 is Cys-AlaSer-Gly-Ser-Pro-Gly-Ala-Arg-Ser-Ala-Ser-Ser-Leu-Ala; p151 is CysHis-Pro-Val-Lys-Ala-Leu-Asp-Phe-Arg-Thr-Pro-Ala-Lys-Ala; and p247 is Cys-Ser-Gly-Ser-Lys-Glu-Lys-Asp-Lys-Ser-Leu-Arg-Arg-Ile-Thr.

For production of antisera, the peptides were conjugated to keyhole limpet hemocyanin (KHL) using MBS, a heterobifunctional reagent linking the thiol group of cysteine on the peptide and the free amino groups of the protein carrier. The peptide-KLH $(2.5 \mathrm{mg}$ in Freund's adjuvant) for each peptide was injected intradermally in each of two adult guinea pigs. Serum samples were drawn prior to immunization and 10-14 d after each boost injection. After three boosts, the animals were deeply anesthetized with sodium pentobarbital and killed by exsanguination.

Only the antisera for p34 were characterized further because only p34 lacked homology with the other opioid subtypes cloned subsequently (Li et al., 1993; Reisine and Bell, 1993; Wang et al., 1993; Yasuda et al., 1993). The conjugated p34 peptide was bound to a microtiter plate for use in the ELISA monitoring of the specificity and titer of the antiserum. At a dilution of $10^{-2}$, ELISA assays showed that the antiserum of one of the two guinea pigs had a binding of $\mathrm{A}_{485}=$ 1.25 , whereas that of the second guinea pig was $\mathrm{A}_{485}=0.8$. The first higher-titer antiserum was characterized by immunodot-blot analysis along with immunohistochemical labeling in NG-108 cells and in the ng

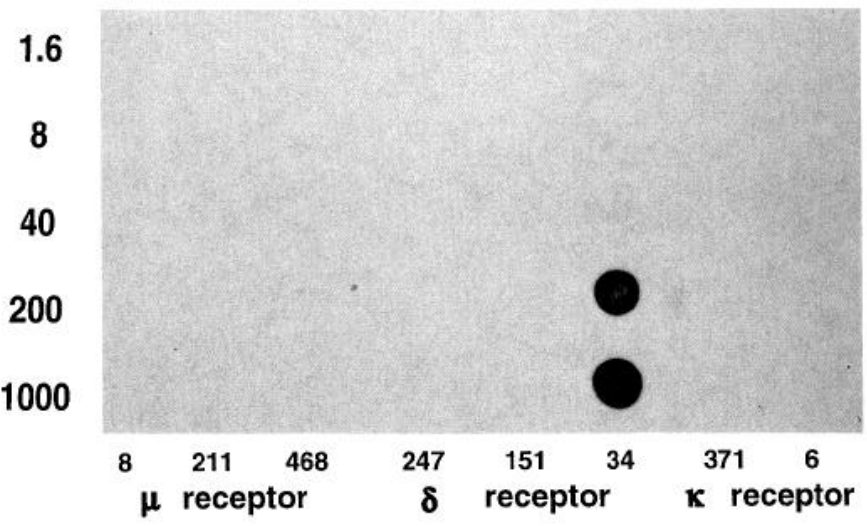

ng

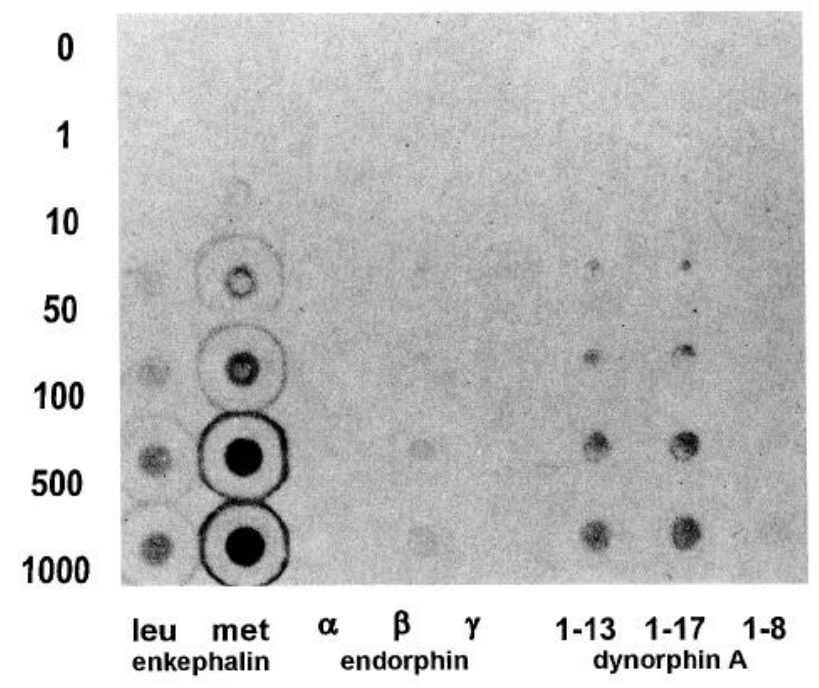

Figure 1. Top, Immunodot-blot analysis showing specificity of the DOR p34 antiserum. Serial dilutions of the unconjugated DOR peptides, p34, p151, and p247, were blotted onto filter paper and incubated with a 1:2000 dilution of guinea pig antiserum raised to DOR p34 or peptide fragments corresponding to segments of the $\mu$ - and $\kappa$-opioid receptor. A dense immunoreaction product is seen only against the immunizing DOR p34 peptide at concentrations of 8-1000 ng. No significant crossreaction with other $\mu$-or $\kappa$-opioid receptor peptide fragments is evident. Bottom, Immunodot-blot analysis depicting the crossreactivity between a 1:30,000 dilution of a rabbit polyclonal antiserum against $\mathrm{ME}$ and varying concentrations $(0-1000 \mathrm{ng})$ of $\mathrm{Leu}^{5}$-enkephalin, ME, endorphins, and dynorphins.

dorsal horn of the spinal cord. The NG-108 cells are known to have about $10^{5}$ DORs per cell (Hazum et al., 1979). In addition, DORs are known to have a high abundance in the superficial layers of the dorsal horn in the spinal cord as seen with autoradiographic localization of binding sites (Goodman et al., 1980; Gouarderes et al., 1993).

Dot-blot analysis. Immunodot-blot analysis (Larsson, 1981) was used to show the specificity of the higher-titer antisera against p34 and ME. The p34 antiserum was characterized for crossreactivity against unconjugated peptides corresponding to amino acid segments of the DOR from the extracellular segment at the N-terminus (p34), the second cytoplasmic loop (p151), or the third cytoplasmic loop (p247). In addition, p34 antiserum was characterized for crossreactivity to segments of the cloned rat $\mu$ - and guinea pig $\kappa$-opioid receptors (Fig. 1, top). For the $\mu$-opioid receptor, peptide fragments corresponding to amino acids 821 (from the extracellular N-terminus; Cys-Thr-Ser-Asp-Cys-Ser-AspPro-Leu-Ala-Gln-Ala-Ser), 211-225 (from the second extracellular loop; Cys-Arg-Gln-Gly-Ser-Ile-Asp-Cys-Thr-Leu-Thr-Phe-Ser-His-Pro), and 368-384 (from the carboxyl terminus; Cys-Gln-Asn-Thr-Arg-Glu- 

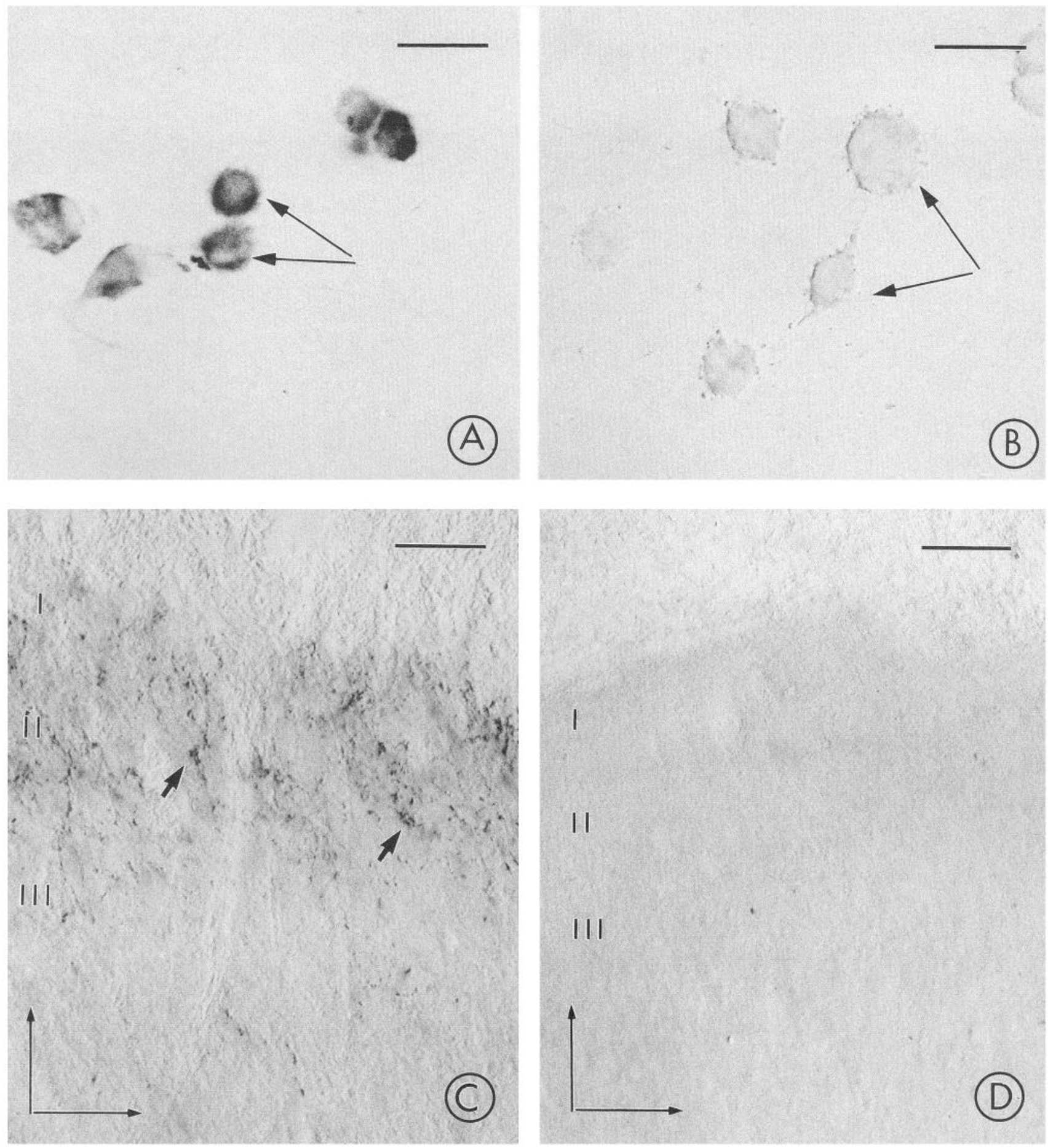

Figure 2. Photomicrographs showing DOR labeling and adsorption controls. A, NG-108 cells expressing high amounts of DOR exhibit dense cytoplasmic immunoperoxidase product after incubation with antiserum to DOR p34 and processing by the ABC method. $B$, NG-108 cells processed with antiserum preadsorbed with $500 \mu \mathrm{g} / \mathrm{ml}$ of the cognate peptide are devoid of peroxidase labeling. $C$, Coronal section through layers I and II within the cervical spinal cord (C2-C4) show DOR p34 localization within punctate varicosities (arrows) in layers I-III of the dorsal horn. D, A comparable section through the spinal cord immunoreacted following preadsorption of antiserum with the cognate peptide is devoid of label. Corner arrows point medial (right) and dorsal (up). Scale bars: $A, B, 25 \mu \mathrm{m} ; C, D, 50 \mu \mathrm{m}$. A, B, standard light microscopy. $C$, $D$, Nomarski optics.

Figure 3. Ultrastructural localization of DOR p34 peroxidase product in unmyelinated axons and axon terminals within layers I and II of the dorsal horn. A, An axon terminal (DRt) exhibits intense DOR-LI. The axon terminal labeled for DOR p34 forms a synapse (open arrow) with an unlabeled dendrite $(U d)$. The plasma membrane near to the synapse of DRt shows dense peroxidase product (small arrow). The DOR p34 peroxidase 

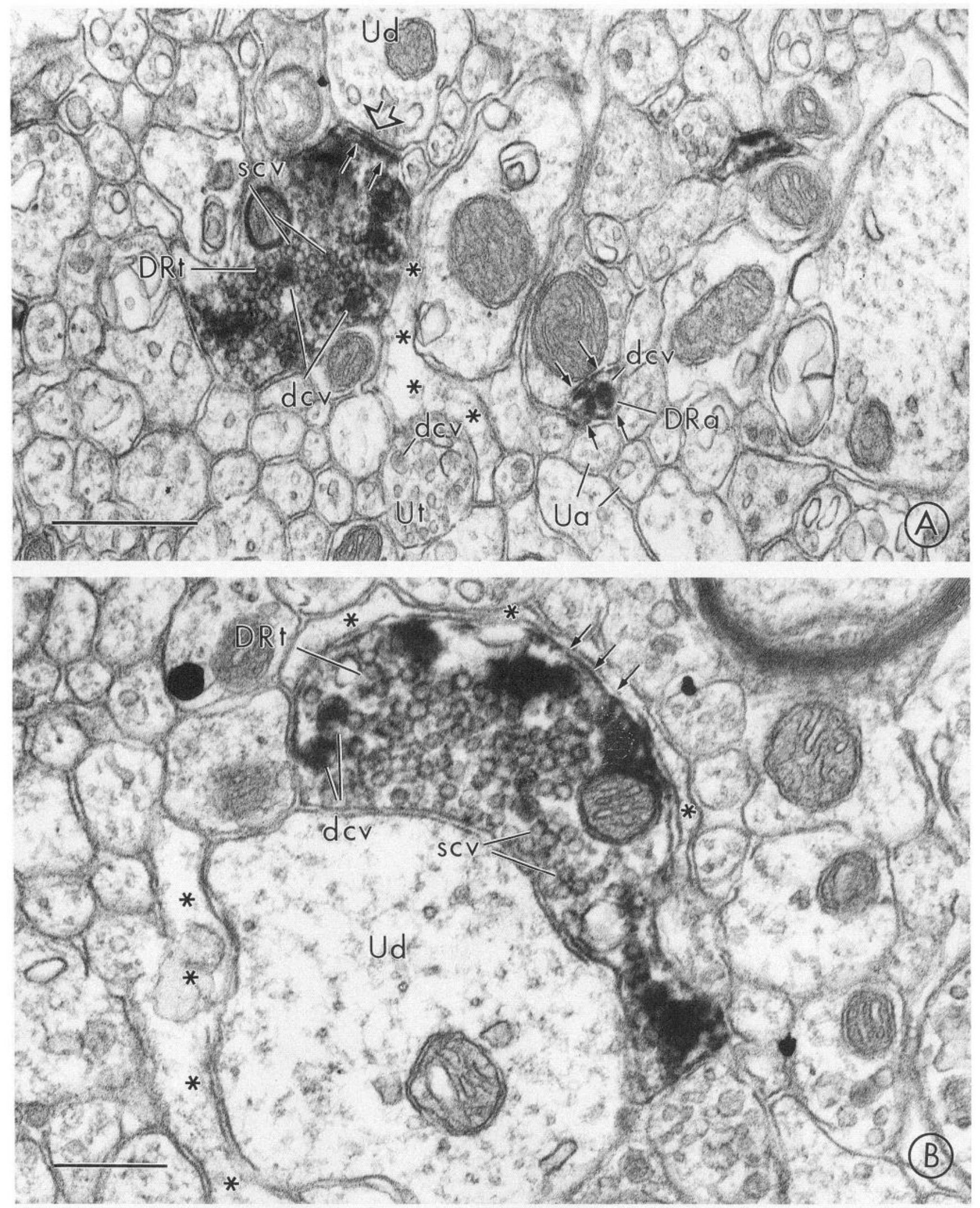

reaction product is localized intensely to dense core vesicles $(d c v)$ within the terminal and nearby small unmyelinated axons $(\mathrm{DRa})$. DOR-LI p34 is also localized to the plasma membrane (small arrows) of the unmyelinated axons. Within the same field, other small unmyelinated axons (Ua) and axon terminals $(U t)$ exhibit no detectable immunoperoxidase reaction product. B, At higher magnification, within an axon terminal (DRt) that is apposed to an unlabeled dendrite $(U d)$, DOR p34 immunoreactivity is prominently localized throughout large dense core vesicles $(d c v)$ and rims small clear vesicles $(s c v)$. Plasma membrane (small arrows) in the axon terminal both near and distal to the dendritic contact also shows dense peroxidase product for DOR p34. The adjacent apposed glial process (*) is without detectable immunoreactivity. Scale bars: $A, 0.5 \mu \mathrm{m} ; B, 0.25 \mu \mathrm{m}$. 
His-Pro-Ser-Thr-Ala-Asn-Thr-Val-Asp-Arg-Thr) were tested. For the $\kappa$-opioid receptor, peptide fragments corresponding to amino acids 618 (from the extracellular N-terminus; Gln-Gly-Pro-Ala-Gln-Pro-AlaSer-Glu-Leu-Pro-Ala-Arg) and 371-380 (from the carboxyl terminus; Arg-Asn-Val-Asp-Gly-Val-Asn-Lys-Pro-Val) from the carboxyl terminus were tested. Peptides were blotted onto membranes and the membranes further processed by combining an enhanced chemiluminescent method (Dupont) and a previously published dot-blot procedure (Larsson, 1981).

The rabbit antiserum (Incstar) to ME was characterized for antibody titer and for crossreactivity against several members of the opioid family of peptides (Fig. 1, bottom). Peptides were blotted onto membranes and the membranes further processed using modifications of a previously published avidin-biotin peroxidase immunoblot procedure (Larsson, 1981).

Tissue preparation. Detailed protocols for fixation and immunocytochemical labeling most compatible with the localization of antisera against peptides within receptor proteins have been published (Sesack et al., 1994). The cultured NG-108 cells were fixed by immersion for $30 \mathrm{~min}$ in $4 \%$ paraformaldehyde for light microscopy. For light and clectron microscopy, adult male Sprague-Dawley rats $(200-300 \mathrm{gm})$ were deeply anesthetized with sodium pentobarbital $(50 \mathrm{mg} / \mathrm{kg}$ i.p.) and perfused through the ascending aorta with $50 \mathrm{ml}$ of $3.75 \%$ acrolein in $2 \%$ paraformaldehyde, followed by $200 \mathrm{ml}$ of $2 \%$ paraformaldehyde. The cervical spinal cords $(\mathrm{C} 2-\mathrm{C} 4)$ of these animals were removed and postfixed for $30 \mathrm{~min}$ in $2 \%$ paraformaldehyde. Fixatives were prepared in $0.1 \mathrm{M}$ phosphate buffer (PB) at a pH of 7.4. Coronal sections (30$50 \mu \mathrm{m}$ in thickness) through the cervical spinal cord $(\mathrm{C} 2-\mathrm{C} 4)$ were cut using a Lancer Vibratome and collected in an ice-cold solution of 0.1 M PB. Tissue sections were then transferred to a $1 \%$ sodium borohydride solution for $30 \mathrm{~min}$ to neutralize aldehydes in sections, and subsequently to $0.5 \%$ bovine serum albumin for another $30 \mathrm{~min}$ to reduce nonspecific binding. The sections were then processed for immunocytochemical labeling.

Single immunoperoxidase labeling for the DOR using $A B C$ method. Aldehyde-fixed NG-108 cells on coverslips or free-floating sections through the spinal cord were incubated for $48 \mathrm{hr}$ at $4^{\circ} \mathrm{C}$ with normal primary or preadsorbed control antiserum against p34. Dilutions of antiserum varying from $1: 100$ to $1: 10,000$ were prepared in $0.1 \mathrm{M}$ Trissaline (TS) containing $0.1 \%$ BSA. Additional sections were also labeled using freeze thawing and/or Triton X-100 to enhance penetration. The detergent was used at $0.25 \%$ for light microscopy and $0.05 \%$ for electron microscopy.

After removal from antisera, the NG-108 cells and spinal cord sections were washed and placed for $30 \mathrm{~min}$ each in (1) biotinylated goat anti-guinea pig $\operatorname{IgG}(1: 400$, Amersham) in $0.1 \% \mathrm{BSA}$, and (2) peroxidase-avidin complex in order to identify the bound guinea pig immunoglobulins. Peroxidase avidin-biotin complex (ABC, Elite Kit) for detection of guinea pig primary antiserum was obtained from Vector Laboratories (Burlingame, $\mathrm{CA}$ ). The peroxidase was visualized by a $6 \mathrm{~min}$ reaction with $3,3^{\prime}$-diaminobenzidine $(22 \mathrm{mg} / 100 \mathrm{ml})$ and $0.01 \%$ hydrogen peroxide. All incubations and washes between each step were carried out in $0.1 \mathrm{M} \mathrm{TS}$, at room temperature with continuous agitation using a Thomas rotator.

Dual immunocytochemical labeling for the DOR and Met'-enkephalin. Immunoperoxidase labeling of the guinea pig anti-DOR antiserum was combined with silver-intensified immunogold labeling of rabbit anti-ME (Chan et al., 1990). After initial preparation of tissue as de- scribed above for single labeling, the Vibratome sections were incubated for $48 \mathrm{hr}$ in a 1:2000 dilution of guinea pig anti-DOR p34 and a 1:20,000 dilution of rabbit anti-ME antibody. These sections were then washed in buffer to remove excess antisera and processed for immunoperoxidase reaction (see above description). Subsequently, the sections were rinsed for $5 \mathrm{~min}$ in $0.2 \%$ gelatin phosphate-buffered saline (PBS) in $0.8 \%$ BSA and incubated for $2 \mathrm{hr}$ in colloidal gold (1 nm)adsorbed anti-rabbit IgG. These were rinsed first in $0.01 \mathrm{M}$ PBS containing $0.8 \%$ BSA, $0.2 \%$ gelatin, then in PBS, and finally placed for 10 $\mathrm{min}$ in $0.2 \%$ glutaraldehyde in $0.01 \mathrm{M}$ PBS. These sections were then rinsed in PBS followed by a wash in $0.2 \mathrm{M}$ citrate buffer, $\mathrm{pH}$ 7.4. To enhance the size of the gold particles for light and electron microscopic visualization, sections were reacted for 6-10 min wilh a silver solution using a light-stable IntenSE kit (Amersham).

NG-108 cells processed on coverslips were dehydrated and attached to glass slides for light microscopic examination. For light microscopy of tissue sections, the sections were mounted on $1 \%$ gelatin-coated glass slides and examined using a Nikon microscope equipped with brightfield or differential interference contrast optics. For electron microscopy, sections were processed using conventional methods (Sesack et al., 1994). Briefly, the immunolabeled Vibratome sections were postfixed for $1 \mathrm{hr}$ in $2.0 \%$ osmium tetroxide in $0.1 \mathrm{M} \mathrm{PB}$ and embedded in Epon. Ultrathin sections through layers I and II of the dorsal horn in the cervical spinal cord $(\mathrm{C} 2-\mathrm{C} 4)$ were cut with a diamond knife. The ribbons of thin sections were collected on grids and counterstained with uranyl acetate and Reynold's lead citrate (Leranth and Pickel, 1989). These were examined with a Philip's 201 electron microscope.

Data analysis. Vibratome sections through layers I and II of the dorsal horn in the rat cervical spinal cord (C2-C4) from three animals showing the most optimal prescrvation of ultrastructure and immunocytochemical labeling were examined for a more detailed qualitative and quantitative analysis of immunoreactive profiles. At the electron microscopic level, two different signals representing eilher inmurboperoxidase product (DOR-LI) or gold-silver particles (ME-LI) were easily distinguishable. Thin sections that contained intense clustering of goldsilver particles or immunoperoxidase product were further analyzed. Neuronal profiles were considered to be positive for ME-LI when the number of gold-silver deposits were at least three times higher then that seen in a comparable region of surrounding neuropil. Whenever possible, the labeling was confirmed in adjacent sections. In regions near the surface of the tissue showing optimal immunogold-silver and immunoperoxidase labeling, the relationship between DOR and ME was quantitatively assessed. Electron micrographs of profiles showing DORLI were first classified with regard to cellular and subcellular localization in neuronal (axons, dendrites, or soma) or glial profiles using nomenclature by Peters et al. (1991). Subsequently, the DOR-IR axons were further examined with respect to their coexistence, appositional, or synaptic associations with ME-labeled and unlabeled structures. Terminals making contact with or in apposition to DAB-labeled profiles were classified according to the presence or absence of a postsynaptic specialization and, if present, the type of junction, whether thin (symmetric) or thick (asymmetric). If a vesicle-containing profile was in contact with another profile but no densities were observed, the two profiles were considered to be nonsynaptically associated.

\section{Results}

Antibody specificity

By immunodot-blot analysis, guinea pig antiserum against DOR p34 (at 1:2000) specifically recognized the immunizing DOR

Figure 4. Ultrastructural localization of DOR-LI p34 to postsynaptic and nonsynaptic sites in dendrites in layers I and II of the dorsal horn. A, Peroxidase labeling for DOR p34 is localized within a dendrite $(D R d)$, postsynaptic to an unlabeled axon terminal $(U t)$. The reaction product is associated with the synaptic specialization $(v)$ and a vesicular structure (curved arrow). The labeled dendrite is apposed to a glial process which is not labeled $(*)$. Within the same field are other unlabeled dendrites $(U d)$. A small unmyelinated axon $(D R a)$ also shows peroxidase product for DOR p34. B, Intense immunoperoxidase product is evident in the dendritic spine (DRsp) at the postsynaptic site ( $v)$ as well as in a vesicular structure (curved arrow). The labeled dendritic spine is also apposed to (open arrowheads) other unlabeled axon terminals (Ut2, Ut3). The single black gold-silver deposit within Ut2 may represent ME-LI but was not sufficiently abundant to allow a positive identification. Within the same section, immunoperoxidase product can be seen localized to a small clear vesicle ( $s c v)$ within a small unmyelinated axon $(D R a)$ which is apposed to other unlabeled small unmyelinated axons $(U a)$. $C$, DOR p34 peroxidase reaction product is localized along a small segment of the plasma membrane of a dendrite opposed by glial processes without noticeable synaptic input within the plane of section. The dendrite is apposed by a glial process which does not contain peroxidase product $\left(^{*}\right)$. A small unmyelinated axon (DRa) shows DR p34 immunoreactivity localized to a large dense core vesicle $(d c v)$ and to the membrane of a small clear vesicle $(s c v)$. Unlabeled unmyelinated axons (Ua) appose the immunoreactive axon. The curved arrow indicates peroxidase immunoreactivity in a vesicular structure in contact with the labeled plasma membrane. $U d$, unlabeled dendrite. Scale bars, $0.25 \mu \mathrm{m}$. 


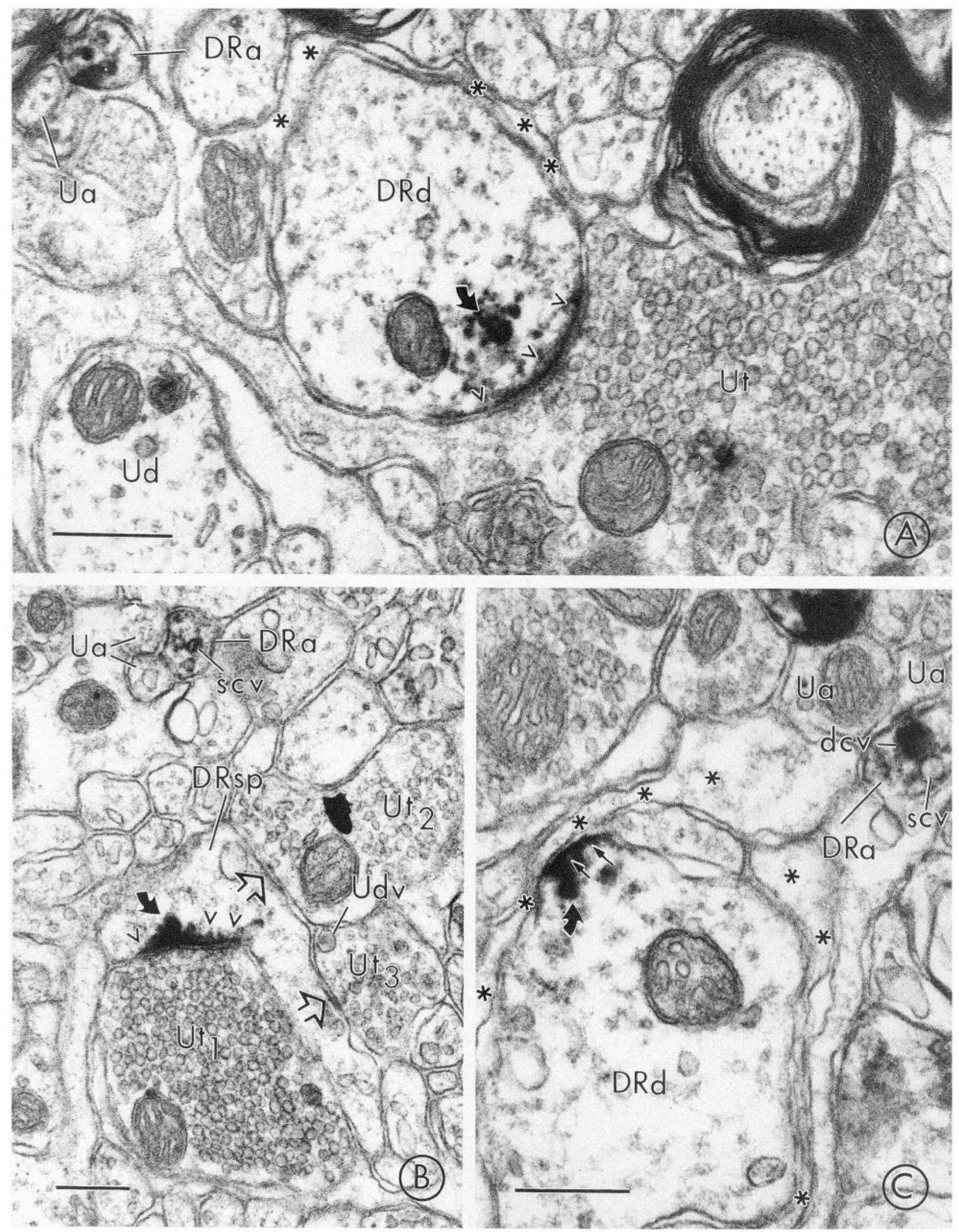


peptide p34 with a threshold of $8 \mathrm{ng}$, but did not crossreact appreciably with other nonimmunizing peptides from adjacent positions on the DOR, nor with peptides from segments of the cloned $\mu$ - or $\kappa$-opioid receptor (Fig. 1, top). Similarly, the ME antiserum principally recognized the parent peptide (Fig. 1, bottom), although some crossreactivity of the $\mathrm{ME}$ antiserum with the dynorphin peptide was observed. Since dynorphin peptides are also prominent within the superficial laminae of the dorsal horn, it is possible that the ME antisera may have some recognition of dynorphin profiles.

As immunocytochemical controls, adsorption of DOR antibody with peptide p34 selectively removed peroxidase reaction product from cultured NG-108 cells and spinal cord sections. At a dilution of 1:2000 of primary antiserum to p34, dense immunolabeling was detected within NG-108 cells (Fig. 2A). Preadsorption of the immune serum with $500 \mu \mathrm{g} / \mathrm{ml}$ of the DOR peptide p34 greatly reduced the intensity of the immunoreaction product (Fig. $2 B$ ). Similarly, cervical spinal cord sections incubated in preimmune serum (not shown) or guinea pig serum preadsorbed with the immunizing DOR p34 peptide also lacked the peroxidase labeling seen with the unadsorbed primary antisera (compare Fig. $2(\mathrm{C}$ and $D$ ).

\section{Localization of DOR-LI to unmyelinated axons and axon terminals}

Intense peroxidase product for DOR-LI was specifically localized to punctate varicose processes within laminae I and II of the dorsal horn as seen by light microscopy (Fig. 2C). More ventral portions of the dorsal and ventral horns contained few labeled fibers. Only light, diffuse labeling could be detected in lamina III or deeper layers. However, a noticeable concentration was observed in layer $X$, surrounding the central canal. Peroxidase was not readily detectable in the white matter located dorsally to lamina I (Fig. 2C).

Within layers I and II of the dorsal horn in the cervical spinal cord (C2-C4), electron microscopy confirmed that DOR-LI was primarily localized presynaptically in unmyelinated axons $(0.1-$ $1.5 \mu \mathrm{m}$ ) and axon terminals (Fig. $3 A$ ). These profiles constituted $84 \%(136 / 164)$ of the total population of DOR-IR profiles examined.

Subcellular localization. Within the unmyelinated axons and axon terminals, the peroxidase reaction product was intensely localized membrane and also the central lumen of dcvs (Fig. 3). As seen in single sections, these vesicles were relatively few in number (usually $1-2$ in small axons and 8-10 in an axon terminal). The dcvs were primarily distributed around the peripheral portion of the axon terminal, away from the synaptic specialization. More rarely, labeled dcvs were detected near presynaptic junctions.

In Figure $3 B$, higher magnification of an axon terminal shows
DOR-LI located continuously along the dcv and a segment of the plasma membrane. Other portions of the plasma membrane often showed dense patches of labeling (Fig. 3A). Presynaptic specializations were only occasionally immunoreactive (Fig. $3 A$ ). In many axons and axon terminals, immunoperoxidase could also be localized to membranes of numerous small (40$50 \mathrm{~nm}$ ) clear vesicles (scv) and a few larger $(80-150 \mathrm{~nm})$ clear vesicles.

Morphological heterogeneities. The DOR-IR terminals were heterogeneous with respect to their neuronal associations. Of the axon terminals containing exclusively DOR-LI, irrespective of their labeling, 56/79 displayed a synaptic contact or apposition to dendrites while $23 / 79$ showed no evidence of dendritic associations. A detailed study of the 56 labeled boutons in contact with dendrites showed that $32 \%$ formed asymmetric synaptic junctions (Fig. 3A), and 5\% formed symmetric synapses. The remainder were apposed, but lacked recognizable synaptic specializations as seen in Figure $3 B$.

\section{Dendritic localization}

Approximately 9\% (15/164) of DOR-IR profiles were dendrites. Within dendrites, DOR-LI appeared most heavily associated with the plasmalemmal surface and postsynaptic densities of small dendrites and dendritic spines (Fig. 4). The postsynaptic densities were largely asymmetric (Fig. $4 A, B$ ). However, the intense immunolabeling may have contributed to the apparent asymmetry. The osmium-enhanced peroxidase reaction product was recognized along dendritic membranes by comparison with neighboring unlabeled junctions within the neuropil. The unlabeled axon terminals in contact with DOR-IR junctions were usually medium-large ( $>1 \mu \mathrm{m}$ in cross-sectional diameter) and contained abundant round vesicles (see Fig. 6).

DOR-LI within dendrites could also be detected at sites of the plasmalemmal surface with no observable synaptic contacts with axon terminals (Fig. 4C). At synaptic and nonsynaptic sites, subsurface organelles near segments of the plasma membrane were most intensely labeled. Near the immunoreactive plasma membrane, dense granular particles were also intensely labeled. These were seen near both synaptic and nonsynaptic portions of the membrane.

\section{Localization of $M E-L I$ relative to $D O R-L I$}

In dually labeled sections through layers I and II of the cervical spinal cord (C2-C4), axon terminals contained ME-LI only, DOR-LI only, or both DOR-LI and ME-LI (Fig. 5). Within the population of axon terminals containing ME-LI, 34\% (12/35) showed no detectable DOR-LI. The gold-silver deposits, indicative of ME, were usually $50-100 \mathrm{~nm}$ in diameter and thus often obscured underlying vesicles having similar or smaller diame ters. However, the gold-silver particles appeared to be more fre-

\footnotetext{
Figure 5. Electron Inicrographs exhibiting the colocalization of peroxidase immunoreactivity for the DOR-LI and immunogold labeling for MELI in layer I and II of the dorsal horn. A, Peroxidase immunoreactivity for DOR p34 $(D R)$ and immunogold-silver labeling for ME $(E)$ are colocalized in the axon terminal to the right of the figure. Another axon terminal contains only gold-silver $(E)$, and small axons $(D R a)$ contain only DOR. Immunoperoxidase labeling is prominently associated with the core and membranes of large dense core vesicles $(d c v)$ and the membranes of smaller clear vesicles $(s c v)$, while gold-silver particles for $\mathrm{ME}(E)$ are associated primarily with large dense core vesicles in dually and singly labeled axons. Unlabeled dcvs and scvs are seen in an unlabeled axon terminal (Ut) making an asymmetric synaptic contact (open arrow) with an unlabeled dendrite. Small unmyelinated axons within the same field are unlabeled $(U a)$. B. Another example of peroxidase immunoreactivity for DOR p34 and immunogold-silver labeling for ME colocalized in an axon terminal. A nearby dendrite exhibits DOR p34 immunoperoxidase activity localized to the plasma membrane (arrows) and a vesicular organelle (curved arrow) within the cytoplasm. Isolated gold-silver grains are seen in DOR dendrite $(D R d)$ and unlabeled terminals $(U t)$, but are too low in abundance for classification as ME-IR. *, Unlabeled glial process. Scale bars: $A$, $0.25 \mu \mathrm{m} ; B, 0.5 \mu \mathrm{m}$.
} 

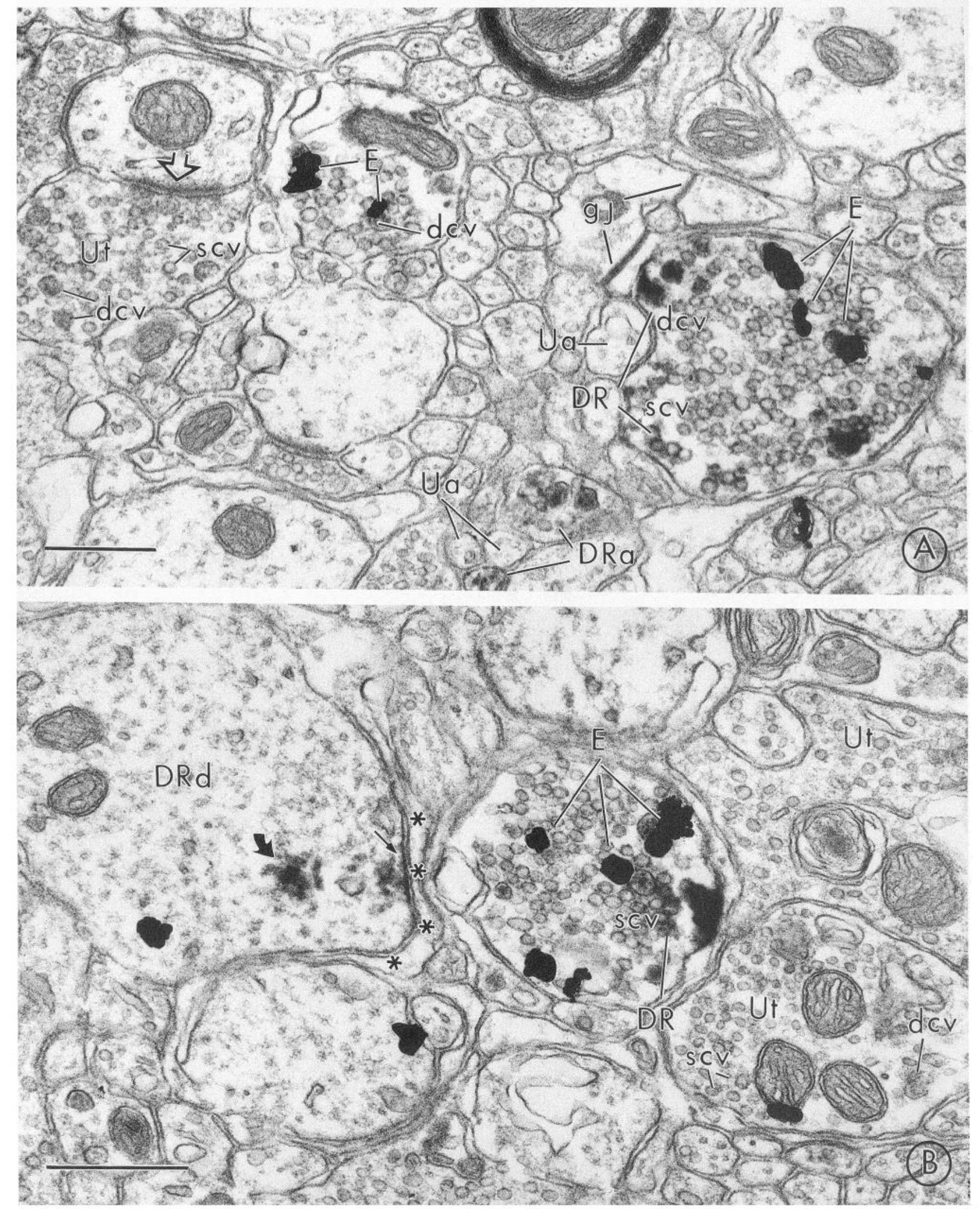
quently associated with devs (Figs. $5 A, 6 B$ ). In addition, many axon terminals containing only ME-LI were apposed to unlabeled, unmyelinated axons and less frequently to myelinated axons and unlabeled or DOR-IR axon terminals.

A higher proportion, comprising of about $23 \%(23 / 102)$ of identified DOR-IR terminals, were without colocalized immunogold-silver labeling for ME (Fig. 6C). In axon terminals containing exclusively DOR-LI, the peroxidase reaction product was prominently associated with devs and the membranes of scvs as discussed above in the single-labeling study. In addition to their dendritic associations, these axon terminals were apposed to axon terminals containing ME-LI, DOR-LI plus MELI, and to other unlabeled axon terminals.

Of the remaining terminals, 23/139 contained both ME-LI and DOR-LI. Of these, three formed an asymmetric and one a symmetric synapse with unlabeled dendrites. However, the vast majority were apposed to dendrites without recognizable junctions. Within the population of dually labeled axon terminals, 19\% were apposed to other axon terminals containing both DOR-LI and ME-LI, 24\% were apposed to axon terminals with DOR-LI (see example, Fig. 6A), and 57\% were apposed to unlabeled axon terminals.

\section{Discussion}

Our results provide several complementary lines of evidence that DOR-LI detected with p34 antiserum recognizes the DOR. The ultrastructural localization of the DOR-LI in a heterogeneous population of axon terminals both with and without ME-LI provides the first morphological evidence for presynaptic autoreceptor and heteroreceptor function of the DOR in the spinal cord of the dorsal horn. Additionally, the prominent vesicular localization of DOR-LI implicates these organelles in the intracellular transport of the receptor.

\section{Methodology}

Antibody specificity. In the present study, we have referred to the localization as DOR-LI to acknowledge the possibility that the guinea pig antisera raised against the N-terminus of the DOR may recognize other structurally similar proteins. However, we believe that the protein identified by the DOR p34 antiserum is likely to be the DOR based on the following criteria: (1) by dotblot analysis, the antiserum recognized only the peptide sequence corresponding to the N-terminus of the DOR; (2) selective, adsorbable immunocytochemical labeling was seen in $\mathrm{NG}$ 108 cells and within layers I and II of the dorsal horn; and (3) the pattern of labeling by this DOR p34 antiserum in the dorsal horn is similar to that shown by peptide immunocytochemistry for the endogenous DOR ligands, enkephalins (Conrath-Verrier et al., 1983). Additionally, the distribution agrees with recent reports on the immunocytochemical localization of the DOR
(Dado et al., 1993), as well as localization of opioid binding sites obtained with autoradiography (Zajac et al., 1989; Gouarderes et al., 1993). Layers I and II of the dorsal horn are highly immunoreactive while only light, diffuse labeling could be observed in the deeper layers of the gray matter with noticeable labeling within layer $\mathrm{X}$. The DOR peptide fragment p34 was likely to have served as a DOR-specific immunogen since by using the Pearson Lipman search for similarity, it was found to have homologies no greater than $64 \%$ to other peptides when aligned to current entries in the GenBank and EMBL data base.

Penetration of antisera. Quantitative analysis of immunolabeled profiles in tissue labeled prior to plastic embedding can lead to erroneous results due to incomplete penetration of antibodies and/or secondary immunoreagents (Leranth and Pickel, 1989). The relative abundance of peroxidase and immunogold labeling may also be underestimated due to differences in penetration of peroxidase versus gold probes and to differing sensitivities of the methods (Chan et al., 1990). In our quantitation of immunoreactive profiles in tissues dually labeled for DOR and ME, care was taken to examine only the most superficial portions of the section containing both immunoreactivities. However, it is still likely that the relative number of DOR- or ME-IR profiles were underestimated. The DOR is present in low abundance and is also extremely labile, being highly sensitive to detergents (Loh and Smith, 1990). This may account for our observation that the most optimal labeling was seen following fixation with acrolein in the absence of Triton $X-100$. This rapid and strong fixation method has previously been shown to be advantageous for both neuropeptides and peptide fragments of G-protein-coupled receptors (King et al., 1983; Aoki and Pickel, 1992; Sesack et al., 1994).

\section{Presynaptic localization}

In the present study, by light microscopy, DOR-LI was immunocytochemically localized to varicose processes within lamina I and II of the dorsal horn in the cervical spinal cord (C2-C4). This distribution is consistent with a primary role of the DOR in somatosensory afferent transmission (Glaum et al., 1994). In addition, the general distribution of DOR-LI reported here is in agreement with the results of recent studies, obtained at low magnification, using autoradiography (Gouarderes et al., 1993) and immunofluorescence (Dado et al., 1993).

Our results establish by electron microscopy that DOR-LI is present principally within axon terminals in laminae I and II of the rat cervical spinal cord (C2-C4). Although not definitive, this localization is consistent with localization of DOR within primary afferents. Previous studies indicate that DOR can be localized in primary afferents based on findings that dorsal rhicotony or peripheral nerve section induces a dramatic decrease in opioid binding sites at the level of the dorsal horn (Lamotte

\footnotetext{
Figure 6. Electron micrographs showing appositions between DOR and ME immunoreactive axon terminals. A terminal containing sparse DOR $\mathrm{p} 34(D R t)$ is apposed to another terminal which is lightly immunoperoxidase labeled for DOR p34 (DR) and also contains gold-silver labeling for ME $(E)$. The peroxidase reaction product is localized to dense core vesicles $(d c v)$, small clear vesicles $(s c v)$, and discrete segments of the plasma membrane (small arrows). B. Two DOR p34 immunoperoxidase-labeled terminals (DRtI, DRt2) are apposed to each other, and another DOR-IR terminal (DRt) is apposed to an ME-IR terminal $(E)$. The peroxidase product for DR p34 is associated with dcv but also rims the scvs. The goldsilver particles of ME $(E)$ are also primarily associated with dcvs. The DRt terminal makes asymmetric synapses with two unlabeled dendrites (open arrow), while the DRt 2 forms an asymmetric synapse (open arrow) with an unlabeled dendrite. Note in this terminal, the dcvs are near the lateral borders of the presynaptic membrane. C, Two axon terminals showing DOR-LI (DRtI, DRt2) are closely apposed to each other and to another unlabeled terminal $(U t)$. Within the labeled terminals, the immunoperoxidase reaction product is prominently associated with dcv and discontinuous segments of the plasma membrane in DRt2 (small arrows). Other unlabeled dense core vesicles (Udcv) as well as labeled dense core vesicles $(d c v)$ can be seen in an adjacent axon terminal. Ua, small unmyelinated axons. Scale bars, $0.5 \mu \mathrm{m}$.
} 

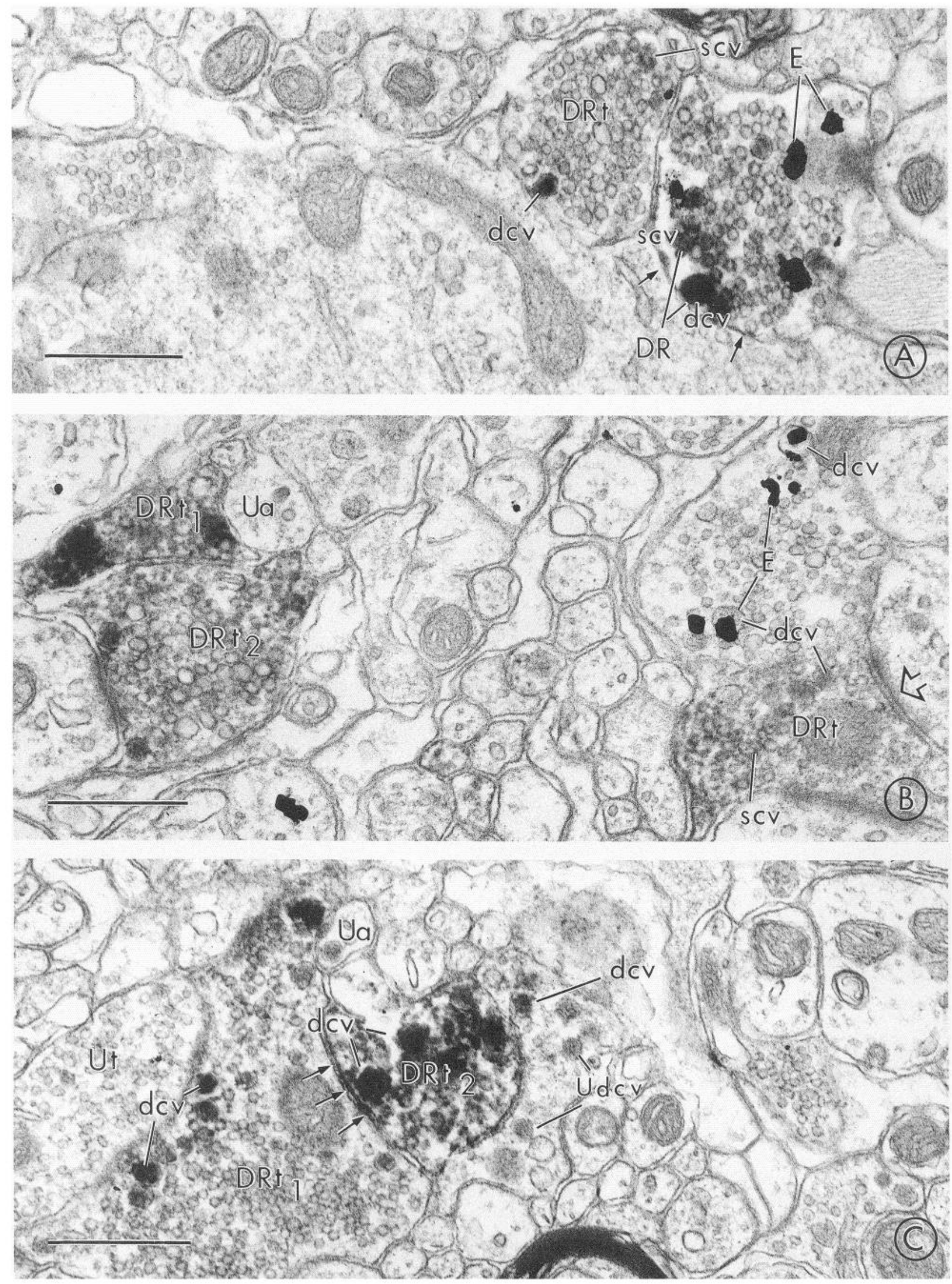
et al., 1976; Jessell et al., 1979; Ninkovic et al., 1982; Daval et al., 1987; Zajac et al., 1989). The majority of these afferents use glutamate and/or substance $P$ as a transmitter and form asymmetric (excitatory type) functions. The dcvs in primary afferent have been shown to contain substance P (Pickel et al., 1977) and numerous studies have demonstrated that opioids inhibit the release of substance P (Jessell and Iversen, 1977). Further dual labeling studies are needed to determine whether the DOR is colocalized with substance $\mathrm{P}$ and/or glutamate. The more intensely DOR-IR terminals could also represent primary afferents. However, they are more likely to be collaterals of local neurons or other central afferents (Hylden et al., 1989; Morgan et al., 1991).

\section{Plasmalemmal and vesicular localization}

In the present study, DOR-LI was intensely localized to dcvs and more infrequently to intermittent segments of axonal plasmalemma, the presumed site of action of opioids. Such patches were found at axoaxonic and axodendritic appositions, but were also seen along surfaces apposed to glia. The present results are consistent with ultrastructural study of DOR in the dorsal horn of the rat spinal cord using monoclonal anti-idiotypic antibodies, which showed distribution of DOR mainly to cell membranes as well as a small subpopulation of synaptic vesicles of axon terminals (Zerari et al., 1994). The difference in the relative abundance of DOR in the ccll membrane and subcellular sites between the present study and the anti-idiotypic study may reflect an inherent difference between an antibody raised specifically against a fragment of the receptor versus an anti-idiotypic antibody. In addition, the differences in labeling could possibly be attributed to differences in the antibody titer, the fixation procedure used, or differences in the penetration of the antibody.

The intense vesicular localization of DOR-LI and the diversity and paucity of DOR-LI along the axonal plasmalemma in the present study raises the possibility that in unstimulated axons, the DOR receptor is principally retained in intracellular vesicular compartments and becomes incorporated into the membrane during exocytotic release of transmitters or peptide modulators. The present localization of DOR-LI in devs of unmyelinated axons also suggests that these organelles may be involved in transport of the receptor from the soma to the axon terminal. This is supportcd by studics showing a large buildup of receptors proximal to a ligature of the vagus nerve. Accumulation of devs has also been shown proximal to ligations in peripheral sympathetic nerves. Labeling in neuronal soma was not observed in the present study of DOR in the dorsal horn, but has been observed in the CNS with anti-idiotypic antibodies directed against DORs (Zerari et al., 1994). Presumably, this difference may reflect lower levels of DOR-LI or formation in neuronal soma in peripheral ganglia or other central afferents. The present results are consistent with those findings as well as with previous speculations that certain presynaptic receptors are associated with dcvs (Laduron, 1984).

An alternative possibility to account for the intense DOR labeling of dcvs is that the receptor may participate in exocytotic release of transmitters from the vesicles. All opioid receptor subtypes are thought to be coupled to $\mathrm{G}$-proteins, probably $\mathrm{G}_{\mathrm{i}}$ since all threc opioid receptor subtypes, $\mu, \delta$, and $\kappa$, inhibit adenylyl cyclase (Childers, 1991). The G-proteins, initially believed to be exclusively present in the plasma membrane, have also been found to be associated with intracellular membrane compartments. Recently, the ultrastructural localization of a subunit of the $\mathrm{G}_{\mathrm{i}}$-protein was reported to be present along plasma membranes and in axon terminals with the immunoreactivity product appearing on plasma membranes and heavily on the membranes of synaptic vesicles (Aronin and Di Figlia, 1992). Although little is presently known about the association of G-proteins with secretory vesicles, a complete set of G-proteins, including $\alpha-, \beta-$, and $\gamma$-subunits, was localized to large dcvs from bovine adrenal medulla (chromatitin granules) and small synaptic vesicles from rodent and bovine brain (Ahnert-Hilger et al., 1994). It is thought that these proteins are associated with various $\mathrm{mcm}$ brane trafficking processes including regulated secretion (Bomsel and Mostov, 1992). Whether the opioid receptors are colocalized with the G-proteins to these vesicles or the membrane remains to be determined. Members of the G-protein family functionally associated with opiate receptors have been localized to membranes of synaptic vesicles (Aronin and Di Figlia, 1992) and implicated in formation, transport, and exocytosis of secretory vesicles (Bourne, 1988; Tooze et al., 1990). This possibility is consistent with our localization of DOR-LI to the small synaptic vesicles.

\section{Presynaptic association of DOR-LI with ME-LI}

The present study provides the first ultrastructural evidence that terminals showing ME-LI in the dorsal horn can also contain DOR-LI, with approximately $25 \%$ of the axon terminals that show DOR-LI also colocalizing ME-LI. This raises the possibility that autoreceptor function can be a feature of the DORmediated effects by opiates in the spinal cord. Alternatively, since DOR-LI could be localized in axon terminals seemingly independent of any relationship with ME-LI, either through colocalization or through appositions with other neuropils containing ME-LI, the possibility arises that the axon terminals containing DOR-LI may be activated by endogenous opiates other than ME in neighboring axons, or by ME located at some distance away from the DOR-LI axon terminal.

\section{Dendritic association of DOR-LI}

DOR-LI in this study was localized occasionally to postsynaptic sites opposing terminals without detectable ME-LI and to nonsynaptic sites along the plasmalemma of dendrites. This suggest that $\mathrm{ME}$ is not the ligand for the postsynaptic DOR or that ME is derived from a more distal terminal. The specific accumulation of DOR-LI at asymmetric synapses formed by unlabeled terminals is of interest relative to a potential interaction of opioid with other transmitters. This localization is reminiscent of that seen with $\beta$-adrenergic receptors in the cerebral cortex, which are responsive to nonsynaptically released norepinephrine (Aoki and Pickel, 1992). The $\alpha$-adrenergic agonist, clonidine, is also well known for its utility in treating the withdrawal signs of opiates. Thus, the actions of the enkephalins at the DOR may subserve similar modulatory roles in the spinal cord. The frequent observation of granular or vesicular organelles near sites of synaptic or nonsynaptic plasmalemmal labeling in dendrites is of interest relative to potential transport of the receptor. These organelles had less clearly defined perimeters then dcvs found in axons. However, they may also play a role in transport of the receptor to the cell surface. Alternatively, they may represent sites for retrieval of internalized DOR.

\section{References}

Abood ME, Noel MA, Farnsworth JS, Tao Q (1994) Molecular cloning and expression of a delta-opioid receptor from rat brain. $\mathbf{J}$ Neurosci Res 37:714-719. 
Ahnert-Hilger G, Schaefer T, Spicher K, Grund C, Schultz G, Wiedenmann B (1994) Detection of G-protein heterotrimers on large dense core and small synaptic vesicles of neuroendocrine and neuronal cells. Eur J Cell Biol 65:26-38.

Andersen RK, Lund JP, Puil E (1978) Enkephalin and substance P effects related to trigeminal pain. Can J Physiol Pharmacol 56:216222.

Aoki C, Pickel VM (1992) C-terminal tail of beta-adrenergic receptors: immunocytochemical localization within astrocytes and their relation to catecholaminergic neurons in $\mathrm{n}$. tractus solitarii and area postrema. Brain Res 571:35-49.

Aronin N, Di Figlia M (1992) The subcellular localization of the G-protein $\mathrm{Gi}$ alpha in the basal ganglia reveals its potential role in both signal transduction and vesicle trafficking. J Neurosci 12:3435-3444.

Atweh SF, Kuhar MJ (1983) Distribution and physiological significance of opioid receptors in the brain. $\mathrm{Br}$ Med Bull 39:47-52.

Belcher G, Ryall RW (1978) Differential excitatory and inhibitory effects of opiates on non-nociceptive and nociceptive neurones in the spinal cord of the cat. Brain Res 145:303-314.

Bennett GJ, Ruda MA, Gobel S, Dubner R (1982) Enkephalin immunoreactive stalked cells and lamina IIb islet cells in cat substantia gelatinosa. Brain Res 240:162-166.

Bomsel M, Mostov K (1992) Role of heterotrimeric G proteins in membrane traffic. Mol Biol Cell 3:1317-1328.

Bourne HR (1988) Do GTPases direct membrane traffic in secretion? Cell 53:669-671.

Chan J, Aoki C, Pickel VM (1990) Optimization of differential immunogold-silver and peroxidase labeling with maintenance of ultrastructure in brain sections before plastic embedding. J Neurosci Methods 33:113-127.

Childers SR (1991) Opioid receptor-coupled second messenger systems. Life Sci 48:1991-2003.

Collin E, Mauborgne A, Bourgoin S, Chantrel D, Hamon M, Cesselin $\mathrm{F}$ (1991) In vivo tonic inhibition of spinal substance $\mathrm{p}$ (-like material) release by endogenous opioid(s) acting at delta receptors. Neuroscience 44:725-731.

Conrath-Verrier M, Dietl M, Arluison M, Cesselin F, Bourgoin S, Hamon M (1983) Localization of Met-enkephalin-like immunoreactivity within pain-related nuclei of cervical spinal cord, brainstem and midbrain in the cat. Brain Res Bull 11:587-604.

Dado RJ, Law PY, Loh HH, Elde R (1993) Immunofluorescent identification of a delta-opioid receptor on primary afferent nerve terminals. Neuroreport 5:341-344

Daval G, Verge D, Basbaum AI, Bourgoin S, Hamon M (1987) Autoradiographic evidence of serotonin 1 binding sites on primary afferent fibres in the dorsal horn of the rat spinal cord. Neurosci Lett 83:71-76.

Duggan AW, Hall JG, Headley PM (1977) Enkephalins and dorsal horn neurones of the cat: effects on responses to noxious and innocuous skin stimuli. Br J Pharmacol 61:399-408.

Evans CJ, Keith DE Jr, Morrison H, Magendzo K, Edwards RH (1992) Cloning of a delta opioid receptor by functional expression. Science 258:1952-1955.

Fields HL, Emson PC, Leigh BK, Gilbert RF, Iversen LL (1980) Multiple opiate receptor sites on primary afferent fibres. Nature 284:351353.

Glaum SR, Miller RJ, IIammond DL (1994) Inhibitory actions of delta 1-, delta 2-, and mu-opioid receptor agonists on excitatory transmission in lamina II neurons of adult rat spinal cord. J Neurosci 14: 4965-497I.

Go VL, Yaksh TL (1987) Release of substance $p$ from the cat spinal cord. J Physiol (Lond) 391:141-167.

Goodman RR, Snyder SH, Kuhar MJ, Young WS III (1980) Differentiation of delta and mu opiate receptor localizations by light microscopic autoradiography. Proc Natl Acad Sci USA 77:6239-6243.

Gouarderes C, Tellez S, Tafani JA, Zajac JM (1993) Quantitative autoradiographic mapping of delta-opipid receptors in the rat central nervous system using [125I][D-Ala2]deltorphin-I. Synapse 13:231240.

Grudt TJ, Williams JT (1994) Mu-opioid agonists inhibit spinal trigeminal substantia gelatinosa neurons in guinea pig and rat. J Neurosci 14:1646-1654.

Hazum E, Chang KJ, Cuatrecasas P (1979) Opiate (enkephalin) receptors of neuroblastoma cells: occurrence in clusters on the cell surface. Science 206:1077-1079.
Hunt SP, Kelly JS, Emson PC (1980) The electron microscopic localization of methionine-enkephalin within the superficial layers (I and II) of the spinal cord. Neuroscience 5:1871-1890.

Hylden JL, Anton F, Nahin RL (1989) Spinal lamina i projection neurons in the rat: collateral innervation of parabrachial area and thalamus. Neuroscience 28:27-37.

Jessell TM, Iversen LL (1977) Opiate analgesics inhibit substance P release from rat trigeminal nucleus. Nature 268:549-551.

Jessell T, Tsunoo A, Kanazawa I, Otsuka M (1979) Substance P: depletion in the dorsal horn of rat spinal cord after section of the peripheral processes of primary sensory neurons. Brain Res 168:247259.

Kangrga I, Randic M (1991) Outflow of endogenous aspartate and glutamate from the rat spinal dorsal horn in vitro by activation of lowand high-threshold primary afferent fibers. Modulation by muopioids. Brain Kes 553:347-352.

Kieffer BL, Befort K, Gaveriaux-Ruff C, Hirth CG (1994) The deltaopioid receptor: isolation of a cDNA by expression cloning and pharmacological characterization. Proc Natl Acad Sci USA 91:1193.

King JC, Lechan RM, Kugel G, Anthony EL (1983) Acrolein: a fixative for immunocytochemical localization of peptides in the central nervous system. J Histochem Cytochem 31:62-68.

Laduron PM (1984) Axonal transport of muscarinic receptors in vesicles containing noradrenaline and dopamine-beta-hydroxylase. FEBS Lett 165:128-132.

Lamotte C, Pert CB, Snyder SH (1976) Opiate receptor binding in primate spinal cord: distribution and changes after dorsal root section. Brain Res 112:407-412.

Larsson LI (1981) A novel immunocytochemical model system for specificity and sensitivity screening of antisera against multiple antigens. J Histochem Cytochem 29:408-410.

Le Bars D, Guilbaud G, Jurna I, Besson JM (1976) Differential effects of morphine on responses of dorsal horn lamina $V$ type cells elicited by $a$ and $c$ fibre stimulation in the spinal cat. Brain Res 115:518524

Leranth C, Pickel VM (1989) Electron microscopic pre-embedding double immunostaining methods. In: (Heimer L, Zaborszky L, eds), pp 129-172. New York: Plenum.

Li S, Zhu J, Chen C, Chen YW, Deriel JK, Ashby B, Liu-Chen LY (1993) Molecular cloning and expression of a rat kappa opioid receptor. Biochem J 295:629-633.

Loh HH, Smith AP (1990) Molecular characterization of opioid receptors. Annu Rev Pharmacol Toxicol 30:123-147.

Morgan CW, de Groat WC, Felkins LA, Zhang SJ (1991) Axon collaterals indicate broad intraspinal role for sacral preganglionic neurons. Proc Natl Acad Sci USA 88:6888-6892.

Ninkovic M, Hunt SP, Gleave JR (1982) Localization of opiate and histamine H1-receptors in the primate sensory ganglia and spinal cord. Brain Res 241:197-206.

Pickel VM, Reis DJ, Leeman SE (1977) Ultrastructural localization of substance $P$ in neurons of rat spinal cord. Brain Res 122:534-540.

Randic M, Miletic V (1978) Depressant actions of methionine-enkephalin and somatostatin in cat dorsal horn neurones activated by noxious stimuli. Brain Res 152:196-202.

Reisine T, Bell GI (1993) Molecular biology of opioid receptors. Trends Neurosci 16:506-510.

Ribeiro-da-Silva A, Pioro EP, Cuello AC (1991) Substance P- and enkephalin-like immunoreactivities are colocalized in certain neurons of the substantia gelatinosa of the rat spinal cord: an ultrastructural double-labeling study. J Neurosei 1 1:1068-1080.

Sesack SR, Aoki C, Pickel VM (1994) Ultrastructural localization of D2 receptor-like immunoreactivity in midbrain dopamine neurons and their striatal targets. J Neurosci 14:88-106.

Sumal KK, Pickel VM, Miller RJ, Reis DJ (1982) Enkephalin-containing neurons in substantia gelatinosa of spinal trigeminal complex: ultrastructure and synaptic interaction with primary sensory afferents. Brain Res 248:223-236.

Tooze SA, Weiss U, Iluttner WB (1990) Requirement for GTP hydrolysis in the formation of secretory vesicles. Nature 347:207-208.

Wang JB, Imai Y, Eppler CM, Gregor P, Spivak CE, Uhl GR (1993) Mu opiate receptor: cDNA cloning and expression. Proc Natl Acad Sci USA 90:10230-10234.

Willcockson WS, Chung JM, Hori Y, Lee KH, Willis WD (1984) Effects of iontophoretically released peptides on primate spinothalamic tract cells. J Neurosci 4:741-750. 
Yaksh TL (1993) The spinal action of opioids. In: Opioid, II, Handbook of experimental pharmacology (Herz A, ed), pp 53-90. Berlin: Springer.

Yaksh TL, Frederickson RC, Huang SP, Rudy TA (1978) In vivo comparison of the receptor populations acted upon in the spinal cord by morphine and pentapeptides in the production of analgesia. Brain Res 148:516-520

Yasuda K, Raynor K, Kong H, Breder CD, Takeda J, Reisine T, Bell GI (1993) Cloning and functional comparison of kappa and delta opioid receptors from mouse brain. Proc Natl Acad Ści USA 90: $6736-6740$.
Zajac JM, Lombard MC, Peschanski M, Besson JM, Roques BP (1989) Autoradiographic study of mu and delta opioid binding sites and neutral endopeptidase-24.11 in rat after dorsal root rhizotomy. Brain Res 477:400-403.

Zerari F, Zouaoui D, Gastard M, Apartis E, Fischer J, Herbrrecht F, Cupo A, Cucumel K, Conrath M (1994) Ultrastructural study of delta-opioid receptors in the dorsal horn of the rat spinal cord using monoclonal anti-idiotypic antibodies. J Chem Neuroanat 7:159-170.

Zieglgansberger W, Tulloch IF (1979) The effects of methionine- and leucine-enkephalin on spinal neurones of the cat. Brain Res 167:5364 